\title{
Alternatives to the use of antibiotics in egg productions
}

\begin{abstract}
The use of antibiotics to regulate the intestinal health of laying hens is widely used. However, there is a need to replace them. The research based on the direct and indirect effects of the prophylactic use of antibiotics on egg production. The search for alternatives such as essential oils, probiotics, prebiotics, organic acids, enzymes, among others been made. In this paper, the possibilities of non-use of antibiotics in laying hens will indicated in order to produce eggs without antibiotics.
\end{abstract}

Keywords: additives, eggs, poultry farm

\author{
Volume I Issue 5 - 2017 \\ Matheus Ramalho de Lima,' Fernando \\ Guilherme Perazzo Costa, ${ }^{2}$ Elizangela Bonfim \\ de Oliveira, ${ }^{3}$ Renata Gomes da Silveira \\ Deminicis, ${ }^{3}$ Daniel Sales do Nascimento,' \\ Talía Silva Ribeiro' \\ 'Federal University of South of Bahia, Brazil \\ ${ }^{2}$ Federal University of Paraíba, Brazil \\ ${ }^{3}$ State University of Santa Cruz,Animal Science, Brazil
}

\author{
Correspondence: Matheus Ramalho de Lima, Federal \\ University of South of Bahia, Jorge Amado highway, Itabuna, \\ Bahia, Brazil, Tel +55-73-9 919-0908, \\ Emailmrlmatheus@gmail.com
}

Received: October 30, 2017| Published: December II, 2017

Abbreviations: MOS, mannan-oligo-saccharides; FOS, fructo oligo-saccharides; IP6, phytic acid phytate

\section{Introduction}

The use of antibiotics in egg production may be, through in therapy, prophylactic use and to improve the performance of the hens. The latter is perhaps the most interesting for the defense of the use of antibiotics, however, its use promotes direct and indirect effects. Among the direct effects, the elimination of pathogens from the gastrointestinal tract, and indirectly effects, improvement in nutrient absorption, lower energy and protein expenditure, lower ammonia production, and a lower rate of food passage, and others. Among the harmful effects on production, besides eliminating pathogenic bacteria, they also eliminate all intestinal floras. Further, their use may mask certain problems from the poultry farm, such as biosecurity. In addition, and perhaps the most recently addressed, prophylactic use may promote bacterial resistance. ${ }^{1}$

\section{Aim}

In this context, the search for alternatives to performanceenhancing antibiotics is necessary. There is a wide variety of viable alternatives for antibiotic substitution, and these alternatives may even promote improvements in product quality. However, some egg farmers ask themselves: "How to maintain the health of the hens, maintaining quality in production, without the use of antibiotics?" Our objective is to present some aspects related to the subject and to show results of substitutes for antibiotics.

\section{Alternatives to the use of antibiotic performance enhancers}

\section{Essential oils}

The essential oils are alternatives to the use of antibiotic growth promoters in poultry, due to their antimicrobial action, besides possessing antioxidant and immunomodulatory properties. ${ }^{2}$ In addition to the pharmacologically active principle, the essential oils consist of mixtures of volatile substances, usually lipophilic, whose components include terpene hydrocarbons, simple alcohols, aldehydes, ketones, phenols, esters, organic acids, etc. ${ }^{3}$ A research ${ }^{4}$ evaluating layers fed with colistin rations $(100 \mathrm{mg} / \mathrm{kg})$, and doses of oregano essential oil (50, 100 and $150 \mathrm{mg} / \mathrm{kg}$ of ration), observed a better egg laying rate and egg weight with $100 \mathrm{mg} / \mathrm{kg}$ of oregano essential oil. Likewise, this treatment promoted a better mass conversion of eggs, with no losses in egg quality, considering Haugh units. In the case of beneficial microorganisms in the cecum, the $100 \mathrm{mg} / \mathrm{g}$ dose of the essential oil promoted a significantly higher population of Lactobacillus and Bifid bacterium, and drastic reduction in the malefic flora of Escherichia coli and Salmonella spp. In this context, it is clearly perceived that essential oils have excellent affinities, thus allowing the complete elimination of antibiotics in poultry rations, since their functions are broad and benefit the entire system, as they act as antimicrobials, antioxidants, antivirals, promote mucus production, stimulate the immune response, are antifungal and antiparasitic. In short, they are excellent additives in the production of antibiotic-free eggs. ${ }^{5}$

\section{Probiotics}

Probiotics constitute living microbial food supplements, capable of beneficially affecting the host, improving the balance of its intestinal micro flora. ${ }^{6}$ Probiotics are living microorganisms whose main function is to stabilize the intestinal micro biota, so they inhibit the growth of pathogenic bacteria (Escherichia coli, Clostridium and Salmonella) and stimulate the growth of beneficial bacteria (Lactobacillus and Bifido-bacterium). Evaluating the histology of the intestine of laying hens fed with red yeast (Sporidiobolus pararoseus), as probiotic, ${ }^{7}$ perceived that the height of the villi was significantly higher with the use of the probiotic in comparison to the control ration. This effect that occurred in a similar way in the three segments of the small intestine, duodenum, jejunum, and ileum. The authors further commented that there is a positive correlation of the inclusion of red yeast in the rations with jejunal villus height, growing linearly ( $y=$ $\left.1.417 x+38.222 ; r^{2}=0.90\right)$. It concluded that the use of probiotic with 
raised bowel villi promotes better intestinal health and efficiency of the functions of that organ. The number of villi and their size in each segment of the small intestine impart to them absorptive capacity, where it is directly proportional to the number of villi present, villi size and surface area available for absorption. ${ }^{8}$

\section{Prebiotics}

They are non-nutrient ingredients, not digestible by birds and that significantly affect the host. They selectively stimulate the growth and activity of one or more species of beneficial intestinal bacteria. Among them, there are several options, such as MOS - extracted from the cell wall of Saccharomyces cerevisiae, FOS - synthesized from Aspergillus niger or Aureobasidium pullulans, and others such as Glycoligosaccharides, Galactoligosaccharides. In the analysis of the doses of MOS in $0.5,1,1.5$ and $2 \mathrm{~g} / \mathrm{kg}$ in the diets, ${ }^{9}$ a greater digestibility of the crude protein verified in all the doses tested in relation to the control without use of the MOS. This effect was potentiated and improved in relation to the lower availability of nutrients to the harmful bacteria, so that their populations was reduced, especially with $1 \mathrm{~g} / \mathrm{kg}$ in Escherichia coli and with $1.5 \mathrm{~g} / \mathrm{kg}$ in Salmonella spp. beneficial effect, especially to the population of Lactobacillus spp. in $1 \mathrm{~g} / \mathrm{kg}$. In the same study, ${ }^{10}$ the authors observed significantly higher rates of egg lying and egg mass at rates of 1 and $1.5 \mathrm{~g} / \mathrm{kg}$. In addition, the authors observed a higher presence of Newcastle antibodies and avian bronchitis at doses greater than $1 \mathrm{~g} / \mathrm{kg}$ tested. Thus, as explained above, prebiotics possess important characteristics that promote beneficial bacterial flora and even stimulate the immune system of birds, enhancing the production system as a whole.

\section{Organic acids}

Organic acids are natural constituents of plants and animals. The acidifiers most used in poultry diets are fumaric, benzoic, butyric, formic, prop ionic, lactic, malic and citric acids ${ }^{11}$ These has a special function of reducing the $\mathrm{pH}$, which makes it an antimicrobial additive, with the ability to regulate the intestinal micro biota and, consequently, to improve digestive efficiency. In summary, organic acids have functions, which, as already mentioned, extend to the stimulation of secretion and enzymatic action, and antifungal. In the case of laying hens fed diets containing butyric and fumaric acid, there was an increase in egg weight in relation to citric, butyric and fumaric acids in layer feedings. Posture rate also had a beneficial effect independent of the organic acid evaluated. The best mass conversion of eggs were observed in birds fed with butyric acid feed, although all acids presented positive results when compared to treatments without using them. In the study by, ${ }^{12}$ the flora of Lactobacillus spp. in the ileum was significantly higher when there was use of the organic acids in relation to the control, with higher rates in the fumaric acid. This shows that organic acid promotes a better balance of intestinal flora, improving and stimulating the health and efficiency of the process of digestion and utilization of the nutrients contained in the ration, without prejudice to the animal performance. Organic acids, although widely used and evaluated, have some limitations that need to be considered, such as types and combinations of acidifiers used, dosages used, and forms of application, type of diet, environmental conditions, and buffer capacity of the ration ingredients.

\section{Enzymes}

The use of exogenous enzymes (amylase, protease, lipase, xylanase, phytase, etc.) has emerged as an alternative to increase the nutritional value and digestibility of feed ingredients for birds. ${ }^{13}$ The enzymes promote a reduction of antinutritional factors of the diet as the viscosity of the digestive content and increase of the degradation of the protein complexes, besides, to help increase the digestibility and the use of food energy, improving the substrate of the commensal bacteria and thus modulating the micro biota. The enzyme xylanase, for example, is responsible for the degradation of non-amidic polysaccharides and is not produce by monogastric animals. ${ }^{13}$ According to ${ }^{14}$ the use of exogenous enzymes, such as phytase, allows alternative ingredients to be as efficient as corn and soy. In a study by, ${ }^{14}$ exogenous phytase supplementation for chickens, over 70weeks of age increased the use of dietary phosphorus, and the birds maintained egg laying. On the other hand, birds that did not receive exogenous phytase in the diet had low posture indexes.

\section{Conclusion}

In the analysis of potentialities and possibilities for the substitution and elimination of antibiotics in rations, we can say that we have innumerable advantages, both for the bird, for the producer, for the consumer and for the environment. The advantages for birds are a better health thanks to a stronger immune system, a lower incidence of intestinal inflammations, promotion of an optimal intestinal flora and lower emissions of ammonia; the results open the possibility of minimizing the therapeutic use of antibiotics. The advantages to the farmer are better digestion of the animals, resulting in a better feed conversion and therefore a lower feed cost and a significant improvement in animal performance, resulting in greater profitability. Resulting to the consumer a guarantee of quality and safety of the food they will consume. In addition, efficient and sustainable use of natural resources thanks to the reduction of emissions of ammonia and methane (up to 50 percent less) and greenhouse gases. In conclusion, we can infer that it is entirely possible to produce eggs free of antibiotics, due to the availability of alternatives for replacing them in the feed of birds, besides not having deleterious effect on the quality and quantity of egg production.

\section{Acknowledgements}

None.

\section{Conflict of interest}

The author declares that there is no conflict of interest.

\section{References}

1. Landers TF, Cohen B, Wittum TE, et al. A Review of Antibiotic Use in Food Animals: Perspective, Policy, and Potential. Public Health Rep. 2012;127(1):4-22.

2. Traesel CK, Lopes STA, Wolkmer CS, et al. Essential oils as substituents of antibiotic growth promoters in broilers: profile of seroproteins and lipid peroxidation. Essential oils as substitutes for antibiotic growth promoters in broilers: seroproteins profile and lipid per Rural Science. 2011;4141(22):278-284.

3. Bona TDMM. Brazilian veterinary research. Brazilian College of Animal Pathology. 2012;32.

4. He X, Hao D, Liu C, et al. Effect of Supplemental Oregano Essential Oils in Diets on Production Performance and Relatively Intestinal Parameters of Laying Hens. American Journal of Molecular Biology. 2017;7:73-85.

5. Chilante RR, Kussakawa KCK, Flemming JS. Effects of the use of essential oils in feeding heavy birds. Academic journal Agrarian and Environmental Sciences. 2012;10(4):387-394. 
6. Fuller R. Probiotics in man and animals. $J$ Appl Bacteriol 1989;66(5):365-378.

7. Tapingkae W, Yindee P, Moonmanee T. Effect of dietary red yeast (Sporidioboluspararoseus) supplementation on small intestinal histomorphometry of laying hens. The Journal of Animal \& Plant Sciences. 2016;26(4):909-915.

8. Macari M. Physiology of the Digestive System of Birds (I). Birds and Eggs. 1999;8(9):2-20.

9. Ghasemian M, Jahanian R. Dietary Mananoligosaccharides Supplementation Could Affect Performance, Immunocompetence, Serum Lipid Metabolites, Intestinal Bacterial Populations, And Ileal Nutrient Digestibility In Aged Laying Hens. Animal Feed Science And Technology. 2017;213:81-89.

10. Gomes FE, Sources DO, Saliba EOS. Fumaric acid and its combination with butyric or formic acids in poultry diets. Brazilian Journal of Veterinary Medicine and Animal Science. 2007;59(5):1270-1277.
11. Kazempour F, Jahanian R. Effects of different organic acids on performance, ileal microflora, and phosphorus utilization in laying hens fed diet deficient in non-phytate phosphorus. Animal Feed Science and Technology. 2017;223:110-118.

12. Brandelli A. Desenvolvimento de ração funcional para aves e suínos através da modificação no farelo de trigo. Porto Alegre: IEL, Brazil; 2012. p. 116

13. Albino FT. Galinhas poedeiras: criação e alimentação. Viçosa: Aprenda Fácil. Brazil; 2014. p. 376.

14. Boling SD, Douglas MW, Johnson ML, et al. The effects of dietary available phosphorus levels and phytase on performance of young and older laying Hens. Poultry Science. 2000;79(2):224-230. 